\title{
BMJ Open Prevalence and factors contributing to dental caries in 12-15-year-old school adolescents in northeast China
}

\author{
Jian Li (10 , ${ }^{1}$ Kaiqiang Zhang, ${ }^{1}$ Zhenfu Lu ${ }^{2}$
}

To cite: Li J, Zhang K, Lu Z. Prevalence and factors contributing to dental caries in 12-15-yearold school adolescents in northeast China. BMJ Open 2021;11:e044758. doi:10.1136/ bmjopen-2020-044758

- Prepublication history for this paper is available online. To view these files, please visit the journal online (http://dx.doi org/10.1136/bmjopen-2020044758).

Received 19 September 2020 Accepted 24 October 2021

\section{Check for updates}

(c) Author(s) (or their employer(s)) 2021. Re-use permitted under CC BY-NC. No commercial re-use. See rights and permissions. Published by BMJ.

${ }^{1}$ Department of Preventive Dentistry, School and Hospital of Stomatology, China Medical University, Liaoning Provincial Key laboratory of Oral Diseases, Shenyang, China

${ }^{2}$ School and Hospital of Stomatology, China Medical University, Liaoning Provincial Key laboratory of Oral Diseases, Shenyang, China

Correspondence to Professor Zhenfu Lu; zflu2006@163.com

\section{ABSTRACT}

Objectives The present study investigated the prevalence and factors contributing to dental caries in 12-15-year-old adolescents in northeast China to provide information for dental caries promotion programmes.

Design, setting and participants A cross-sectional survey including caries examination and questionnaire was performed in Liaoning province, China. 3731 12-15-yearold school adolescents participated in the survey. School adolescents were randomly selected and received a clinical oral examination and completed questionnaires that assessed their oral health-related behaviours and attitudes.

Results Overall, 3731 12-15-year-old school adolescents participated in the survey. The prevalence of dental caries in these adolescents was $53.65 \%$, and the mean number of decayed-missing-filled teeth (DMFT) in the adolescents was $1.64 \pm 2.38$ in northeast China, which was higher than the mean in China as a whole. A remarkable difference in DMFTwas exhibited between age groups, region and gender $(p<0.05)$. Logistic regression analysis showed that age, region, gender and father' education were related to the occurrence of caries in these adolescents.

Conclusion The 12-15-year-old school adolescents assessed exhibited a high prevalence of dental caries and low awareness of oral health. It is critical to protect permanent teeth, and oral and dental health education and promotion should be more comprehensively integrated into school courses for these adolescents.

\section{INTRODUCTION}

Oral disease is one of the most prevalent chronic diseases and an alarming public health problem worldwide. ${ }^{1}$ A WHO analysis reported that oral disease has become a determining factor for quality of life and a global burden on social and economic health, affecting 2.4 billion people, 621 million adolescents worldwide. $^{2}$ The global average decayed-missing-filled teeth (DMFT) in 12-year-old adolescent is $1.86 .^{3}$ Puberty is an important stage of adolescents's growth and development because their physical and mental status gradually mature. Permanent dentition begins to function in the subsequent decades of life. A high prevalence of dental caries may impact adolescents' quality

\section{Strengths and limitations of this study}

This survey is with a good sample size and wide coverage.

- These results would provide valuable information for the local government and policymakers.

- There are no related reports in the past decade in Liaoning Province in China.

- Family income was not included in the questionnaire; therefore, it is difficult to infer the relationship between socioeconomic factor and dental caries.

of life, their reports of pain and absences from school. ${ }^{3}$ Therefore, it is of great importance to learn about the prevalence of dental caries and take effective measures to prevent and intervene in the occurrence of dental caries.

The prevalence of permanent caries in 12-year-old Chinese adolescents was $45.8 \%$ and $28.9 \%$ in 1995 and 2005, respectively. ${ }^{4}$ China is one of the largest developing countries in the world, and it has accomplished great achievements in economic development during the past decades. With the improvement of residents' living standards, daily habits and lifestyles have also changed. However, the oral behaviour, prevalence of dental caries and government control policies vary in different provinces and urban/ rural areas. Therefore, oral health surveys are the primary means of obtaining useful oral health information to provide evidence for public health policy. ${ }^{5}$

Recent research reported the oral health status in different provinces in China, such as the Sichuan province ${ }^{6}$ and Jilin province. ${ }^{7}$ The last survey in Liaoning Province of 12-15-year-old school adolescents was in 2005. ${ }^{3}$ However, there are no related reports in the past decade. The Liaoning Province is located in the northeast of China. Northeast China is a juncture between the Circum-Bohai Sea Economic Zone and the Northeast Economic Zone, which is a centre 


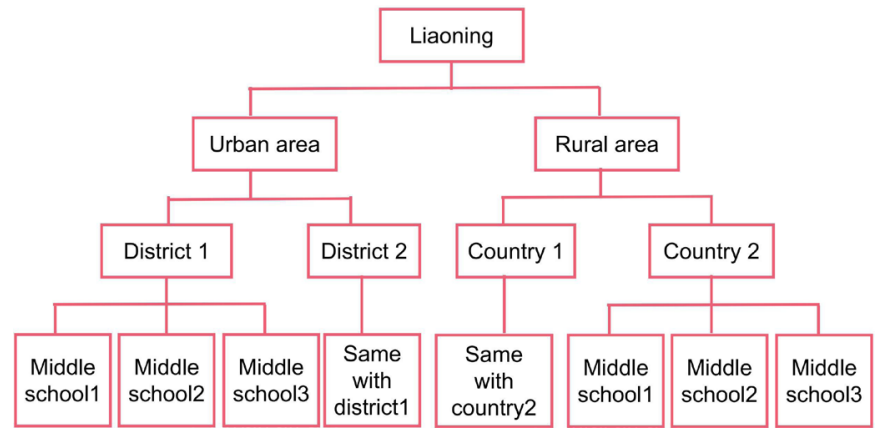

Figure 1 The flowchart of sample selection.

of economy, politics and culture. However, the community oral health services in China remain insufficient, especially in the Northeast, where development lags behind coastal regions. The goal of caries prevention is to reduce the prevalence of caries in 12-year-old adolescents to under $30 \%$ by 2030 in mid and long-term plans for prevention and treatment of chronic diseases issued by the General Office of the State Council of China, ${ }^{8}$ which seems to be a big challenge according to fourth National Oral Health Survey in China. ${ }^{9}$ Therefore, it is extremely urgent to know the prevalence in each region and establish medical and oral healthcare service systems on the basis of current findings and results.

The present study investigated the oral health status and associated factors of 12-15-year-old school adolescents in northeast China. This study provides evidence to help optimise the distribution of oral health resources and promote the development of oral public health.

\section{METHODS}

\section{Sample selection}

This study was performed in Liaoning province, and multistage stratified sampling was used in this study. In the first stage of sampling, districts and counties were considered as strata, and population data were obtained from the 2010 census conducted by National Bureau of Statistics of the People's Republic of China. Two rural counties and two urban districts were randomly selected from each stratum using the probability-proportionalto-size. Finally, four areas (Shenyang, Heping District, Jinzhou Linghe District, Donggang county and Zhuanghe county) were selected. In the second stage, three middle schools were randomly selected from each district (county). In the third stage, cluster sampling method was used to randomly select students aged 12 , 13, 14 and 15 from each middle school. The flowchart is in figure 1.

Participants resided in the survey area for $>6$ months, and ages were calculated based on the survey month. The adolescents' parents signed informed consent forms, which were kept for the record. The sample size was calculated based on the data of the third National Oral Health Survey in $2005,{ }^{10}$ in which the prevalence of dental caries for those aged 12 years was $28.9 \%$. The design effect $(\mathrm{def}=4.5)$, significance level $(\alpha=5 \%)$, margin of error $(\delta=10 \%)$ and non-response rate $(20 \%)$ were also included in the following formula:n $=\operatorname{deff} \frac{\mathrm{u} \alpha / 2^{2}}{\delta^{2}} \mathrm{p}(1-\mathrm{p})$

Based on this estimation, the required sample size for 12-15-year-old in this study was at least 3660. And the same dentists interviewed the adolescents to complete the questionnaires.

\section{Caries examination}

Clinical examinations were performed under artificial light using plane surface dental mirrors and community peridontal index (CPI) probes. Dental caries was diagnosed according to WHO criteria. ${ }^{11}$ The theoretical and clinical training were performed by the technical group responsible for fourth National Oral Health Survey. To ensure the validity and reliability of the data collection, the three examiners were trained in theoretical and clinical knowledge by a standard examiner (the fourth examiner) before the survey. Duplicate examinations were randomly conducted in $5 \%$ of the participants to compare the findings. Moreover, the standard examiner reviewed the data for five of the participants who were assessed by each of the other inspectors. All of the review results were used to calculate a Kappa value. The mean Kappa values used to determine interexaminer reproducibility were 0.85 for the dental caries examination. Then, the qualified dentists performed the oral examinations at health service classroom in local school. The examiners dried the surface of the teeth with cotton balls and swabs while the students were in a supine position.

\section{Questionnaire}

Three questionnaire interviewers who underwent the screening, training and certification by the nation were arranged to collect the questionnaire information as

Table 1 The distributions and numbers of the studied adolescents in Liaoning Province

\begin{tabular}{llcrrl}
\hline Area & City & Numbers of school selected & Male & Female & Total \\
\hline Urban & Shenyang & 3 & $436(11.68 \%)$ & $452(12.11 \%)$ & $1841(49.34 \%)$ \\
& Jinzhou & 3 & $473(12.68 \%)$ & $480(12.87 \%)$ & $1890(50.66 \%)$ \\
\multirow{2}{*}{ Rural } & Donggang & 3 & $469(12.57 \%)$ & $466(12.49 \%)$ & $471(12.62 \%)$ \\
& Zhuanghe & 3 & $481(12.89 \%)$ & $1872(50.17 \%)$ & 3731 \\
\hline
\end{tabular}




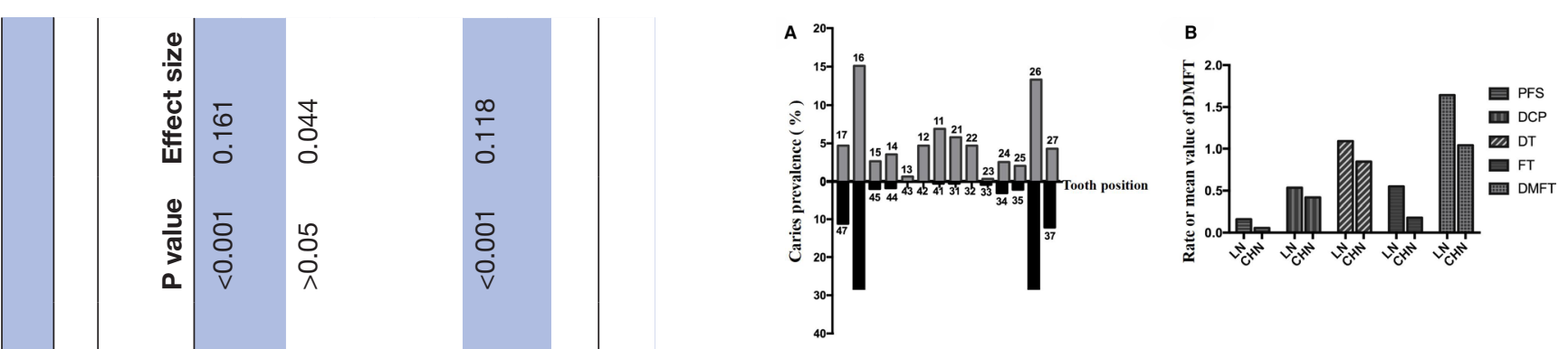

Figure 2 (A) The prevalence of dental caries in different tooth position in the upper and lower jaws. (B) Comparison of pit and fissure sealant rate (PFT), dental caries prevalence (DCP), decayed teeth (DT), filled teeth (FT) and decayedmissing-filled teeth (DMFT) between Liaoning Province (LN) and China (CHN). DT, decayed teeth; LN, liaoning; PFS, Pit and fissure sealant.

efficiently and unbiasedly as possible. The coincidence rate of the questionnaire answers between each interviewers and trainer must exceed $95 \%$. Then, the questionnaire interviewers went to the school classroom and explained the purpose and matters needing attention to the students. The questionnaire was completed by the student independently. The questionnaire included the following aspects: (a) child's family background (gender, sibling and parents educational background), (b) oral health-related behaviour (sweet dessert consumption, frequency of toothbrushing, use of dental floss) and (c) oral health awareness and attitudes of parents or guardians. After completion, the questionnaire interviewers would further check and return the unqualified to the student for further completion.

\section{Data analysis}

A statistical software package (IBM SPSS Statistics, V.20) was used for data analyses. Caries prevalence $(\%)$ and mean DMFT scores were calculated. An independent sample t test (two categories) and one-way ANOVA (more than two categories) were used to assess the statistical significance of the differences in dental caries experience (mean DMFT score). $\chi^{2}$ tests were used to compare proportions. Binary logistic regression was performed to investigate the effects of the independent variables studied on the child's dental caries experience. The dependent variable was dental caries and scored as no dental caries $=0$ and dental caries $=1$. The independent variables were gender, only one child in the family (yes, no), father's educational background (low, median and high), toothbrush habits, sweet consumption, oral health awareness and attitudes. Cohen's Kappa statistic was used to evaluate interexaminer variability for dental caries examination. The statistical significance level for all tests was set at 0.05 .

\section{Patient and public involvement}

It was not appropriate or possible to involve patients or the public in the design, or conduct, or reporting or dissemination plans of our research. 
Table 3 The prevalence of dental caries, rate of pit and fissure sealant and mean value of DMFT with different districts and genders

\begin{tabular}{llllll}
\hline & & & \multicolumn{2}{l}{ Dental caries } & \\
\cline { 3 - 5 } Group & & N (\%) & DMFT (SD) & t/F & P value \\
\hline Sibling & Have & $1240(33.24 \%)$ & $1.86 \pm 2.57$ & -3.952 & $<0.001$ \\
& Do not have & $2491(66.76 \%)$ & $1.53 \pm 2.27$ & & $<0.001$ \\
Father's education & Low (junior school or below) & $2055(55.08 \%)$ & $1.83 \pm 2.46$ & 15.88 & \\
background & Median (senior school) & $880(23.59 \%)$ & $1.49 \pm 2.35$ & & $<0.001$ \\
& High (college or above) & $796(21.33 \%)$ & $1.32 \pm 2.14$ & & \\
Mother's education & Low (junior school or below) & $2051(54.97 \%)$ & $1.85 \pm 2.49$ & 18.36 & $<$ \\
background & Median (senior school) & $902(24.18 \%)$ & $1.49 \pm 2.31$ & & \\
& High (college or above) & $778(20.85 \%)$ & $1.29 \pm 2.07$ & & \\
& & &
\end{tabular}

DMFT, decayed-missing-filled teeth.

\section{RESULTS}

\section{Distribution of the studied adolescents}

A total of 769 12-year olds, 1082 13-year olds, 950 14-year olds and 930 15-year olds were enrolled in this research. There was an equal man-to-woman ratio and an even distribution for urban and rural areas in all age groups. The distribution of all involved factors for the full study sample is presented in table 1 .

\section{Caries experience of the studied adolescents}

Compared with the reference examiner's results, the three examiners demonstrated very good reliability for caries diagnosis, with kappa-coefficient values over 0.80 . The prevalence and severity of dental caries in the studied adolescents are summarised in table 2 . The prevalence of dental caries was $53.65 \%$, and the mean number of DMFT was $1.64 \pm 2.38$. The mean number of decayed teeth was $1.09 \pm 1.97$, the mean missing teeth was 0.01 and the mean filled teeth (FT) was $0.55 \pm 1.34$. The pit and fissure sealant rate was $16 \%$. The prevalence of caries was significantly different between urban and rural areas, males and females and age groups $(\mathrm{p}<0.001)$. The prevalence of dental caries and DMFT values were higher in female adolescents $(59.34 \%$, $1.99 \pm 2.65)$ than male adolescents $(47.87 \%, 1.29 \pm 2.02)$ and higher in rural areas $(61.37 \%, 2.08 \pm 2.73)$ than urban $(45.68 \%, 1.19 \pm 1.87)$ (table 2). A remarkable difference was exhibited between age groups, which indicates that age was an important associated factor with permanent dental caries experience in young Chinese people.

\begin{tabular}{|c|c|c|c|c|c|}
\hline \multirow[b]{2}{*}{ Group } & & \multirow[b]{2}{*}{$\mathbf{N}(\%)$} & \multicolumn{3}{|c|}{ Dental caries } \\
\hline & & & DMFT (SD) & $\mathbf{t} / \mathbf{F}$ & $P$ value \\
\hline \multirow[t]{2}{*}{ Toothbrush habits } & $\geq 2 / d$ & 1301 (38.43\%) & $1.58 \pm 2.36$ & -7.15 & $>0.05$ \\
\hline & $<2 / d$ & $2084(61.57 \%)$ & $1.64 \pm 2.36$ & & \\
\hline \multirow[t]{4}{*}{ Use of dental floss } & No & 2987 (80.04\%) & $1.65 \pm 2.40$ & 1.004 & $>0.05$ \\
\hline & Occasionally & $644(17.26 \%)$ & $1.66 \pm 2.34$ & & \\
\hline & Every week & 48 (1.29\%) & $1.58 \pm 2.49$ & & \\
\hline & Every day & $52(1.39 \%)$ & $1.08 \pm 1.63$ & & \\
\hline \multirow[t]{3}{*}{ Desserts and candies } & $\geq 2$ times/day & $493(13.21 \%)$ & $1.81 \pm 2.51$ & 7.946 & $<0.001$ \\
\hline & $\geq 2$ times/week & 1657 (44.41\%) & $1.76 \pm 2.45$ & & \\
\hline & $<2$ times/week & 1581 (42.37\%) & $1.46 \pm 2.24$ & & \\
\hline \multirow[t]{3}{*}{ Carbonated drinks } & $\geq 2$ times/day & $226(6.06 \%)$ & $1.80 \pm 2.74$ & 3.141 & $<0.05$ \\
\hline & $\geq 2$ times/week & 1103 (29.56\%) & $1.77 \pm 2.28$ & & \\
\hline & $<2$ times/week & 2402 (64.38\%) & $1.57 \pm 2.38$ & & \\
\hline \multirow[t]{3}{*}{ Sugared drinks } & $\geq 2$ times/day & 302 (8.09\%) & $1.62 \pm 2.32$ & 1.459 & $>0.05$ \\
\hline & $\geq 2$ times/week & 1464 (39.24\%) & $1.72 \pm 2.41$ & & \\
\hline & $<2$ times/week & 1965 (52.67\%) & $1.59 \pm 2.36$ & & \\
\hline
\end{tabular}

DMFT, decayed-missing-filled teeth. 
A

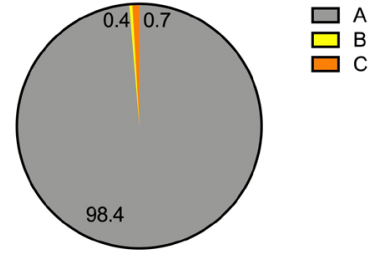

Total percentage $=100 \%$
B

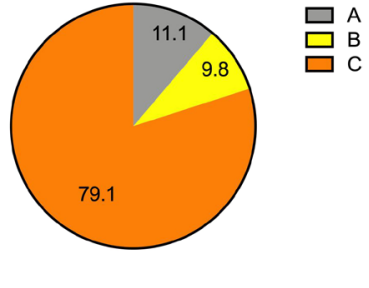

Total percentage $=100 \%$

Figure 3 (A) Use of toothpaste. (A) Yes: 98.4. (B) No: 0.4. (C) Unkonwn: 0.9. (B) Use of toothpaste use. (A) Yes: 11.1. (B) No: 9.8. (C) Unknown: 79.1.

As shown in figure 2A, in the upper and lower jaws, the prevalence of dental caries of the first permanent molar was higher than other teeth. Compared with the China Fourth Oral Health Epidemiological Survey, the prevalence of dental caries, rate of decay tooth, rate of FT, DMFT value and rate of pit and fissure sealant were higher in Liaoning than China (figure 2B).

\section{Results of the questionnaires}

The response rate of questions and completion rate were 100\%. Caries experience (mean DMFT score) according to the different contributing factors studied is shown in tables 3 and 4. Adolescents who had siblings suffered more severe tooth decay than only adolescents $(\mathrm{p}<0.001)$. Caries experience also showed that high educational background of the parents correlated with a lower mean DMFT score of the permanent teeth in their adolescents $(\mathrm{p}<0.001)$.

According to the questionnaire (table 4), about $89.76 \%$ of participants brushed their teeth (figure 3A), and 19.9\% of the studied adolescents used fluoride toothpaste. A total of $38.4 \%$ of adolescents brushed their teeth two times daily, but nearly $77.64 \%$ of adolescents had never used dental floss. A total of $13.21 \%$ of the studied adolescents consumed sweet desserts and candies daily. A statistically significant difference was found between the frequency of sweet food and carbonated drinks $(\mathrm{p}<0.001)$.

As shown in figure 4, 40.68\% of studied adolescents reported that they had visited a dentist in the recent year. The main reason that adolescents sought dental care was treatment of oral pain (49.8). A total of $19.9 \%$ of

A

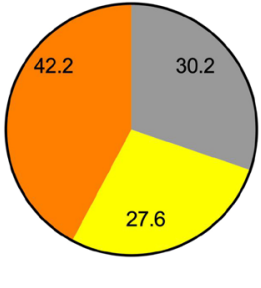

Total percentage $=100 \%$

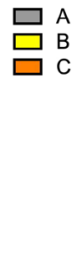

B

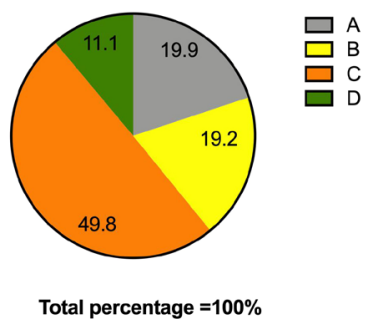

Figure 4 (A)The percentage of time from the last dental visit. (A) Less than 6 months: 30.2. (B) 6-12 months: 27.6. (C) More than 12 months: 42.2. (B) The purpose of last dental visit in 12 months. (A) Consult and examination: 19.9. (B) Prevention: 19.2. (C) Treatment: 49.8. (D) Others: 11.1.

adolescents received regular examinations, and $19.2 \%$ of adolescents received caries prevention.

\section{Results of oral health knowledge and attitude}

Eight questions were used to assess oral health awareness, and four questions assessed attitudes (table 5). 'Fluoride is useful to dental protection' and 'pit and fissure sealant can prevent dental caries of adolescents' were unknown to most respondents, with the lowest correct rates of $49.72 \%$ and $41.82 \%$, respectively. 'Bacteria are one of the causes of inflammation of the gums' and 'sweets can lead to dental caries' were agreed by $76.13 \%$ and $75.12 \%$ of adolescents, respectively. For these eight questions, the accuracy rate of oral health awareness was higher in urban than rural areas. There were statistically significant differences between urban and rural areas on the questions of 'Gum bleeding is normal when brushing your teeth', 'Dental caries are caused by bacteria on teeth', 'Sweets can lead to dental caries' and 'Pit and fissure sealant can prevent dental caries of adolescents'.

For oral health attitudes, $93.18 \%$ of adolescents believed that 'oral health is important to life', and $92.41 \%$ of adolescents believed that 'we should rely mainly on ourselves to prevent oral diseases'. There was no significant difference between urban and rural areas.

\section{Results of the binary logistic regression analysis}

To identify factors affecting dental caries, we analysed the data collected using the questionnaire, including age, gender, parents' education, oral health-related habits and behaviours and knowledge of oral health. For the binary logistic regression analysis, a score of ' 0 ' was assigned to adolescents without dental caries, and a score of ' 1 ' was assigned for adolescents with dental caries. A score of ' 1 ' was assigned to male adolescents, a score of ' 0 ' was assigned to female adolescents. A score of ' 1 ' was assigned to father's low education level, a score of ' 2 ' was assigned to father's medium education level and a score of ' 3 ' was assigned to father's high education level. A score of ' 1 ' was assigned to urban, a score of '2' was assigned to rural. As shown in table 6 , the results of the binary logistic analysis showed that age, regional, gender and father' education factors contributed to the caries experience (caries prevalence) of the studied adolescents $(\mathrm{p}<0.05)$. The prevalence of dental caries was 1.653 times higher in female adolescents than in male adolescents, 95\% CI (1.449 to 1.885). The risk of dental caries increased by 1.068 times as the age increased by 1 year, $95 \%$ CI (1.001 to 1.139 ). The prevalence of dental caries was affected by father's education level. The prevalence of dental caries in the offspring of highly educated fathers decreased to 0.788 times, $95 \%$ CI $(0.658$, to 0.944$)$. And the risk of dental caries in urban adolescents was 1.774 times higher than that in rural adolescents, $95 \%$ CI (1.534 to 2.052). 


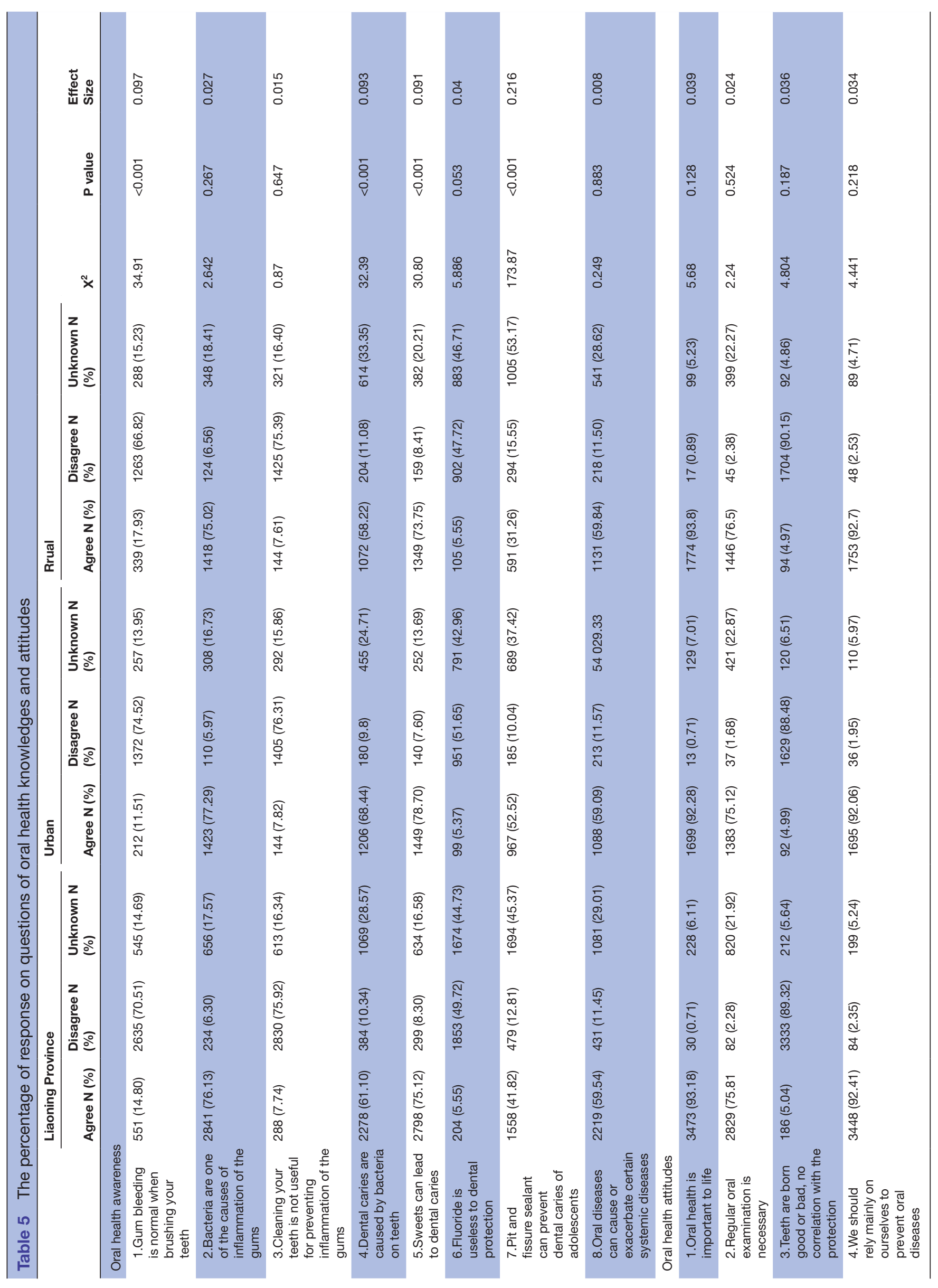


Table 6 Binary logistic regression analysis for the dental caries status of adolescents

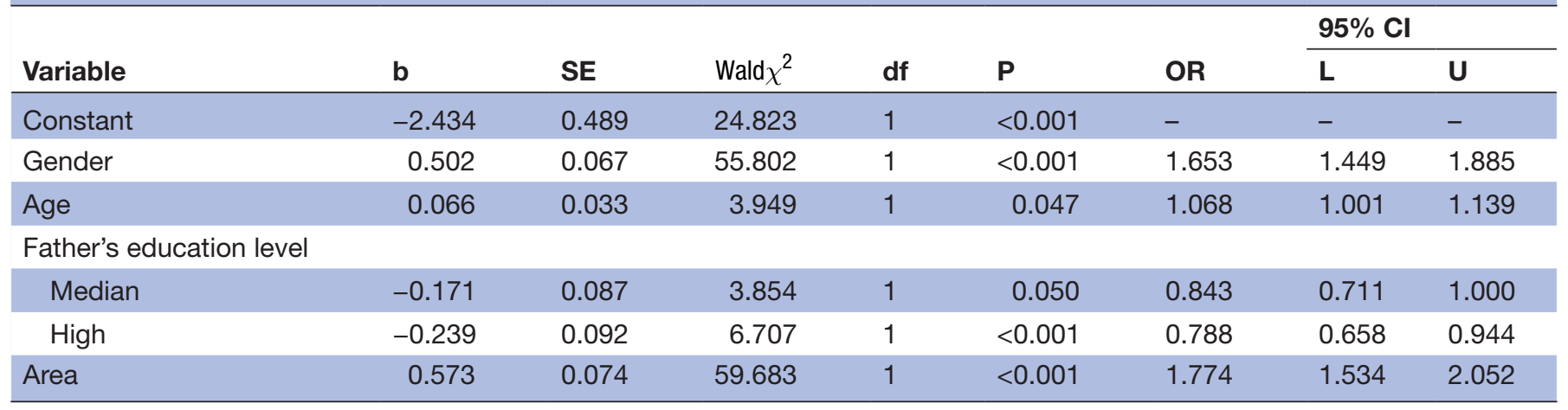

\section{DISCUSSION}

Trends of dental caries in a population may only be observed from long-term epidemiological surveillance and surveys. Over the past two decades, the prevalence of permanent caries in 12-year olds fluctuated between $45.8 \%, 28.9 \%$ and $38.5 \%$ in Chinese adolescents in 1995, 2005 and 2015, respectively. ${ }^{49}$ The prevalence of permanent caries in 12-year olds and 12-15 year olds in Liaoning Province in our study was $51.23 \%$ and $53.65 \%$, respectively, which is much higher than China and other provinces or cities, such as Jilin and Shenzhen. ${ }^{12}$ This prevalence of dental caries is higher in India $(47.2 \%)$ in $2017^{13}$ and Malawi $(19.1 \%, 21.9 \%$ in 12-year old, 15 -year old, respectively) in $2016,{ }^{14}$ while similar to the results in Brazil in 2021. ${ }^{15}$ A similar trend was found in mean DMFT value, which rapidly increased in the past decade. Untreated tooth decay remained at a high level, which was lower than national average. Researches reported that adolescents were more prone to have bad eating habits, ${ }^{16}$ which may be correlated with the prevalence of dental caries.

Our findings indicated that social geographical and gender factors were strongly associated with the prevalence of permanent dental caries in all 12-15-year-old groups and the DMFT values. Logistic regression analysis showed that gender and area were risk factors for dental caries. Adolescents in rural areas had a higher level of caries prevalence and higher DMFT score compared with urban areas. These data are consistent with the fourth National Oral Health Survey and similar national surveys in other countries. ${ }^{17-20}$ These results suggest that more treatments are needed for the rural teenage population.

Logistic regression analysis showed that 12-15-year-old girls had more caries than boys. This result may be because girls' permanent teeth erupt earlier than boys' teeth, ${ }^{21}$ and the examined girls consumed more sweets than the boys. Therefore, the girls' teeth were exposed to sweets earlier and had a greater chance of decaying. ${ }^{22}$ We further found that a low level of father' education was a risk factor for dental caries. We considered that father's education level would influence the family living condition, family environment and attention to adolescents' oral health that greatly affected the prevalence of dental caries. Parents with relatively lower education levels may ignore the oral health of their adolescents and fail to intervene appropriately when an issue arises. ${ }^{23}$ At the same time, the prevalence of dental caries varied with age and increased by 1.068 times as the age increased by 1 year in school adolescents. Parents will pay more attention to only one child and spend more money on food. These parents paid more attention to their child's oral health status because the FT was higher in northeast China. The survey results found that oral health awareness and attitude improved significantly in the past decade, especially in rural areas. ${ }^{10}$ It is concluded that the epidemic characteristics have changed. Several factors, such as the dynamic development of differences in dietary habits, economic levels and access to oral medical resources of urban and rural residents, might have led to changes in caries prevalence and improved awareness in urban and rural areas. However, the awareness of adolescents' parents should be evaluated more because of the high caries prevalence. The government should concerns that dental medical resources, service-level and residents' awareness of oral healthcare in suburban areas are relatively lagging, resulting in the difference of dental caries between urban and rural areas.

The frequency of sugar consumption by the examined adolescents was high, including desserts, candies and carbonated drinks. An acknowledged consensus is that sugar products are implicated in dental caries, and these cariogenic effects were further confirmed in other research. ${ }^{24}$ Our study found that desserts and candies influenced the prevalence of dental caries, but no cause and effect relationship could be concluded. We should draw a close association between all kinds of sugar consumption. The percentage of adolescents for dental visit was $40.68 \%$, and most of these visits were for treatment. Therefore, parental awareness of the adolescents' oral health and the importance of visiting a dentist require more efforts to meet the stated goals.

In conclusion, the prevalence of dental caries in northeast China was serious. And, the present study provides some helpful suggestions for policymakers. Data from this study may enable policymakers to direct interventions towards reducing the prevalence of dental caries in adolescents. Prevention strategies, such as dental examination and preventive attention, should be taken to 
assess the periodical effects of public oral health strategies on addressing these problems. The government should dynamically monitor the incidence, the trend and the distribution characteristics of dental caries, so as to provide scientific basis for the prevention and treatment of dental caries. Under the ambitious goal of 'Healthy China 2030', oral and dental health education and promotion should be more comprehensively integrated into school courses for these adolescents in order to improve the stomatological attainment. The student should master the related knowledge, such as dental caries, periodontal disease and malocclusion. Pit and fissure sealent should cover all the school adolescents in appropriate regions.

Acknowledgements The authors are grateful to all participants, organisers and staff who contributed to the fourth National Oral Health Survey in China. This survey was funded by a grant from Scientific Research in the Public Interest and conducted by the Department of Preventive Dentistry, Hospital of Stomatology, China Medical University, China.

Contributors ZL had acquired funding for the project and played a role in design of the study; JL was involved in drafting and revising the manuscript. KZ had participated in data collection, data analysis of the study. All authors read and approved the final manuscript. ZL was responsible for the overall content as the guarantor.

Funding This study was funded by Scientific Research Fund of National Health Commission of the People's Republic of China (number 201502002).

Competing interests None declared.

Patient and public involvement Patients and/or the public were not involved in the design, or conduct, or reporting, or dissemination plans of this research.

Patient consent for publication Not applicable.

Ethics approval Ethical approval was received by the Stomatological Ethical Committee of Chinese Stomatological Association (approval number 2014-003).

Provenance and peer review Not commissioned; externally peer reviewed.

Data availability statement Data may be obtained from a third party and are not publicly available. No data are available.

Open access This is an open access article distributed in accordance with the Creative Commons Attribution Non Commercial (CC BY-NC 4.0) license, which permits others to distribute, remix, adapt, build upon this work non-commercially, and license their derivative works on different terms, provided the original work is properly cited, appropriate credit is given, any changes made indicated, and the use is non-commercial. See: http://creativecommons.org/licenses/by-nc/4.0/.

ORCID iD

Jian Li http://orcid.org/0000-0003-4858-8539

\section{REFERENCES}

1 Peres MA, Macpherson LMD, Weyant RJ, et al. Oral diseases: a global public health challenge. Lancet 2019;394:249-60.

2 Martins MT, Sardenberg F, Bendo CB, et al. Dental caries remains as the main oral condition with the greatest impact on children's quality of life. PLoS One 2017;12:e0185365.
3 Kassebaum NJ, Bernabé E, Dahiya M, et al. Global burden of untreated caries: a systematic review and metaregression. J Dent Res 2015;94:650-8.

$4 \mathrm{XQ}$ Q. The third national oral health epidemiological survey in China. Beijing: People's Medical Publishing House, 2008.

5 Lu HX, Tao DY, Lo ECM, et al. The 4th national oral health survey in the mainland of China: background and methodology. Chin J Dent Res 2018;21:161-5.

6 Yin W, Yang Y-M, Chen $\mathrm{H}$, et al. Oral health status in Sichuan Province: findings from the oral health survey of Sichuan, 2015-2016. Int J Oral Sci 2017;9:10-15.

7 Du A, Zhang H, Chen C, et al. Oral health of 12-year-old children in Jilin Province, China: a population-based epidemiological survey. Medicine 2019;98:e18463.

8 General Office of the State Council of China. The mid-term and longterm plan for prevention and treatment of chronic diseases (20172025. Beijing: General Office of the State Council of China, 2017.

9 Quan JK, Wang XZ, Sun XY, et al. Permanent teeth caries status of 12- to 15-year-olds in China: findings from the 4th national oral health survey. Chin J Dent Res 2018;21:181-93.

10 Cao C-fan. [Prevalences of periodontal diseases and dental caries in China: re-analysis of the data from the Third National Epidemiological Survey on Oral Health]. Zhonghua Kou Qiang Yi Xue Za Zhi 2013;48:257-9.

11 World Health Organization (WHO). Oral health surveys-basic methods 5th version. Geneva: World Health Organization, 2013.

12 Cheng Y-H, Liao Y, Chen D-Y, et al. Prevalence of dental caries and its association with body mass index among school-age children in Shenzhen, China. BMC Oral Health 2019;19:270.

13 Kumar S, Kumar A, Badiyani B, et al. Oral health impact, dental caries experience, and associated factors in 12-15-year-old school children in India. Int J Adolesc Med Health 2017;29:/j/ijamh.2017.29. issue-2/ijamh-2015-0041/ijamh-2015-0041.xml.

14 Msyamboza KP, Phale E, Namalika JM, et al. Magnitude of dental caries, missing and filled teeth in Malawi: national oral health survey. BMC Oral Health 2016;16:29.

15 Arantes R, Jamieson LM, Frazão P. Dental caries, periodontal disease and restorative dental care among Indigenous and non-Indigenous groups in Brazil: a descriptive study. Community Dent Oral Epidemiol 2021;49:63-9.

16 Ren S, LI Z, WM L. The current survey on dietary habits and the relevant research with obesity among the students in Benxi City. Chinese Journal of Health Education 2016;32:986-8.

17 Christian B, Blinkhorn AS. A review of dental caries in Australian Aboriginal children: the health inequalities perspective. Rural Remote Health 2012;12:2032.

18 Oulis CJ, Tsinidou K, Vadiakas G, et al. Caries prevalence of 5, 12 and 15-year-old Greek children: a national pathfinder survey. Community Dent Health 2012;29:29-32.

19 Panagidis D, Schulte AG. Caries prevalence in 12-year-old Cypriot children. Community Dent Health 2012;29:297-301.

20 Sufia S, Chaudhry S, Izhar F, et al. Dental caries experience in preschool children: is it related to a child's place of residence and family income? Oral Health Prev Dent 2011;9:375-9.

21 Baume LJ. Report on a dental survey among the school population of French Polynesia. population surveyed and numbers of teeth present. Arch Oral Biol 1968;13:787-802.

22 Xiaolan H, Hong P, Yuanyuan L. Investigation and analysis of snack consumption of junior middle school students in Changning district, Shanghai. Health Educ Health Promot 2019;14:232-4.

23 Astrøm AN, Kiwanuka SN. Examining intention to control preschool children's sugar snacking: a study of carers in Uganda. Int $J$ Paediatr Dent 2006;16:10-18.

24 Peres MA, Sheiham A, Liu P, et al. Sugar consumption and changes in dental caries from childhood to adolescence. $J$ Dent Res 2016;95:388-94. 